\title{
Vínculo comercial entre México y Latinoamérica
}

\author{
Commercial relation between Mexico and Latin America \\ Jennifer Espino-Leal ${ }^{a}$, Ruth Ortiz-Zarco ${ }^{b}$
}

\begin{abstract}
:
The objective of this research is to diagnose the current commercial link between Mexico and Latin America, to identify the advantages of greater commercial integration, given the uncertainty of the change in the global geopolitical environment, and consequently the uncertain dynamics of international trade; the study focuses on the analysis of commercial results in Mexico and in each of the countries of Latin America; the 2008-2017 interval was chosen as the study period because, during those years, the economic performance of Latin America has taken into account the favorable ones with the Mexican economy. The results provide empirical evidence that supports the commercial exchange of Mexico with the Latin American region.
\end{abstract}

Keywords:

Geopolitical Environment, Commercial Integration, Latín América, México.

Resumen:

El objetivo de esta investigación es diagnosticar la actual relación comercial entre México y Latinoamérica, para posteriormente identificar las ventajas de una mayor integración comercial, ante la incertidumbre del cambiante entorno geopolítico mundial y la incierta dinámica del comercio internacional; el estudio se concentra en el análisis estadístico de los flujos comerciales entre México y cada uno de los países de América Latina con los que se tiene algún tratado o acuerdo comercial; se eligió como período de estudio el intervalo 2008-2017 debido a que durante esos años el desempeño económico de Latinoamérica tuvo rasgos relativamente favorables en la relación que sostiene con la economía mexicana. Los resultados aportan evidencia empírica que apoya la integración comercial de México con la región Latinoamericana.

\section{Palabras Clave:}

Entorno Geopolítico, Integración Comercial, Latinoamérica, México.

\section{Introducción}

El sistema internacional del siglo XXI, se caracteriza por un cambiante entorno geopolítico, situación que genera incertidumbre en diversos aspectos de la economía mundial; en el caso específico del comercio exterior en México, la secuela se manifiesta en los retos que hoy enfrenta la política exterior del país, la reciente renegociación del Tratado de Libre Comercio con América de Norte (TLCAN) es uno de ellos; el TLCAN se ha convertido en el mayor bloque de libre comercio en el mundo, su renegociación implica una nueva dinámica internacional, proceso ante el cual, la economía mexicana requiere políticas económicas alternas que generen crecimiento y desarrollo económicos, y la política exterior encaminada a fortalecer el comercio exterior es una de ellas; por ello este documento analiza la relación comercial que México mantiene actualmente con Latinoamérica, a fin de aprovechar los acuerdos comerciales que ya se tienen pactados e impulsar nuevas oportunidades de mercado.

La implementación del TLCAN en 1994, sentó las bases que forjaron la actual estrategia de comercio exterior de la economía mexicana; Estados Unidos se ha posicionado como principal cliente y proveedor comercial de México, en 2017 fue el destino del $80 \%$ de las exportaciones mexicanas y el origen del $46.4 \%$ de las importaciones, estás cifras denotan la fuerte integración de los mercados y la elevada dependencia de la economía mexicana frente a la estadounidense. 5

a Estudiante de la Licenciatura en Comercio Exterior, Universidad Autónoma del Estado de Hidalgo, Instituto de Ciencias Económico Administrativas, Email: jenni_33@ hotmail.com

${ }^{\text {b }}$ Profesora Investigadora de la licenciatura en comercio exterior, Universidad Autónoma del Estado de Hidalgo, Instituto de Ciencias Económico Administrativas, Email: ruth_2608@hotmail.com 
México tiene 12 Tratados de Libre Comercio con 46 países, 32 acuerdos para la promoción y protección recíproca de las inversiones con 33 países y nueve acuerdos de alcance limitado (Acuerdos de Complementación Económica y Acuerdos de Alcance Parcial); es decir, se tiene las bases para iniciar un proceso de diversificación de mercados, basado en el fortalecimiento y diversificación de las actividades productivas de México, la diversificación de mercados no es sencilla, pero sí necesaria para aminorar los efectos nocivos de la incertidumbre ante situaciones como la actual renegociación del TLCAN, la cual al día de hoy no es del todo certera pese a que la cámara alta ya tiene en su poder la versión final del acuerdo.

Pese a que México cuenta con una vasta red de acuerdos comerciales, es oportuno analizar cada uno de ellos, con la finalidad de desplegar nuevas oportunidades de mercado y estrategias que permitan aprovechar estas relaciones comerciales; en este momento México tiene 14 acuerdos comerciales con Latinoamérica; este documento lleva a cabo un diagnóstico de las relaciones comerciales que México tiene con Latinoamérica, con la finalidad de identificar y aprovechar los acuerdos comerciales vigentes e incentivar el intercambio comercial, partiendo del análisis de los flujos comerciales existentes, la posterior identificación de posibles mercados en la región que ofrezcan nuevas oportunidades a los agentes económicos, incluyendo exportadores, inversionistas y consumidores.

La hipótesis que sustenta este trabajo afirma que el gobierno y las empresas mexicanas enfrentan el reto de diversificar su intercambio comercial a raíz del proceso de renegociación del TLCAN y de la fuerte dependencia comercial que México mantiene con Estados Unidos; es ineludible explorar el mercado latinoamericano con la finalidad de aprovechar y fortalecer los 14 acuerdos comerciales entre México y Latinoamérica, como estrategia para afrontar las problemáticas políticas, económicas y sociales. Robustecer el comercio con otras regiones del continente Americano, significa una oportunidad para las pequeñas y medianas empresas de posicionar sus productos en mercados extranjeros; ante el actual escenario de acrecentamiento del comercio latinoamericano, es coyuntural voltear a ver estos mercados, y aprovechar las ventajas que tiene México en este mercado.

A la presente introducción se suman tres apartados, el primero concierne a la revisión de la literatura que antecede el presente documento, el segundo analiza la información estadística relativa a los flujos comerciales que México sostiene con Latinoamérica, finalmente se presentan los resultados y conclusiones.

\section{Revisión de la literatura}

La literatura que analiza el comercio entre México y Latinoamérica es bastante amplia, esta sección presenta una breve recopilación de las aportaciones en torno al tema; si bien la mayor parte de ella es coincidente en los beneficios derivados de una mayor integración comercial entre México y América Latina (Puchet, 2007; Luiselli, 2010; Dingemans y Ross, 2012; Granguillhome, 2012; Ramos, 2013; Icaza, 2014; Rubio, 2014; Herrada, 2014; Flores 2016; Covarrubias 2017), existen estudios que resaltan los aspectos negativos de los procesos de integración comercial vivenciados al día de hoy (Heine, 2014; Dussel, 2018;

Puchet (2007), en un recorrido por los acuerdos y tratados que mantiene México con los países de América del Norte y Latinoamérica, muestra los aspectos más relevantes en términos de comercio, inversión y migración, ocurridos en el último cuarto de siglo, tras hacer una valoración sobre cuáles han sido los avances y obstáculos de esos procesos de integración de la economía mexicana hacia al norte y el sur, concluye que México tiene todavía terreno por avanzar para culminar una satisfactoria transición estratégica en el mundo global. 1

Luiselli (2010), analiza la conveniencia de un mayor acercamiento político y económico entre México y Brasil, las dos potencias económicas de América Latina, no sólo en función de la integración latinoamericana, sino de los desafíos que la globalización plantea a ambas naciones, muestra cómo en los últimos años los nexos comerciales y de inversión han crecido aceleradamente y cómo los gobiernos de ambos países han avanzado en el reconocimiento de la importancia de la relación MéxicoBrasil y en el establecimiento de un marco institucional sustentado en una Comisión Binacional de alto nivel. 2 Para Granguillhome (2012), los tratados de libre comercio que México ha negociado con América Latina y el Caribe son instrumentos que liberan, regulan y fomentan el intercambio de bienes y servicios; afirma que son acuerdos son integrales que abarcan temas de propiedad intelectual, de fomento a la inversión e incluyen mecanismos de solución de controversias. Concluye que la creciente interrelación entre la política económica nacional y la política exterior de México hace que nuestra relación económica con América Latina y el Caribe sea cada vez más rica y compleja. 3

Para Dingemans y Ross (2012), los acuerdos de libre comercio firmados por los países latinoamericanos, le han permitido a México la diversificación de sus exportaciones y el incremento del número de socios comerciales, por lo que los acuerdos preferenciales de comercio ofrecen beneficios que promueven las exportaciones de a diversos mercados; no obstante, gran parte del crecimiento exportador en la región ha ocurrido 
en el margen intensivo, no en el extensivo, siendo la expansión hacia nuevos productos y socios comerciales un tanto limitada, consecuentemente los gobiernos deben optar por políticas externas más activas. 4

Ramos (2013), examina las relaciones de México con América Latina en las últimas dos décadas como preámbulo de la creación de la Comunidad de Estados Latinoamericanos y Caribeños (CELAC) y la Alianza del Pacífico (AP), así mismo, detecta las oportunidades y desafíos que estos mecanismos implican para México; concluye que en años recientes México ha dinamizado los vínculos con la región, recuperando espacios de diálogo que se habían perdido, si la economía mexicana logra instituirse como un socio serio, responsable y confiable, adquiere la oportunidad de consolidar su presencia e influencia en la región. 5

México, en su papel de actor con responsabilidad global, ha logrado elevar el nivel de vida de las poblaciones de las regiones prioritarias de Centroamérica y el Caribe a través de la cooperación y el fortalecimiento institucional; el reto de México y las regiones de Latinoamérica es entenderse como una comunidad y no como Estados aislados que comparten fronteras o territorios similares de manera casual. La historia contemporánea de la cooperación de México y las regiones centroamericana y caribeña ha consolidado redes de expertos y bienes públicos, protocolos regionales e inversiones de impacto directo en beneficio de las poblaciones, (Herrada, 2014). 6

Tal como Icaza (2014) lo señala, ante los cambios en el escenario internacional y sus transformaciones internas, México ha tenido que ajustar su política exterior y explorar nuevos tableros para maximizar los beneficios de su plena y abierta integración a la globalidad, la estrategia resultante es una mezcla entre la búsqueda de nuevos socios, la profundización de las relaciones existentes, la participación activa en arreglos formales e informales y el objetivo de convertirse en actor con responsabilidad global. Así mismo, Rubio (2014), tras valorar el bagaje cultural, lingüístico, sociodemográfico y económico que une a México con América Latina y el Caribe, resalta la relevancia de la región en el escenario internacional; el auto considera que México requiere asegurar su posición como actor relevante en la región. 78

Flores (2016) analiza la Alianza del Pacífico (AP) como un mecanismo de integración comercial en América Latina; afirma que si bien, actualmente ya hay resultados concretos en materia de movilidad de bienes, servicios, capitales, personas y cooperación multisectorial; es menester que la AP se profundice con nuevos compromisos enfocados principalmente al área financiera, la facilitación y promoción del comercio, la inversión, el turismo, y la cooperación en áreas innovadoras entre los cuatro países que la conforman y con terceros. 9

Covarrubias (2017), explora cómo México se ha reacomodado en la región Latinoamericana a lo largo de los últimos 16 años al apoyar el libre comercio y al subrayar su identidad democrática; argumenta que el libre comercio ha sido un objetivo constante de la política exterior mexicana y concluye que México cambia y se reacomoda en una América Latina igualmente cambiante y en reacomodo: América Latina pasa del neoliberalismo a la ola rosada y a la crisis, mientras que México lo hace de la euforia democrática a la guerra contra las drogas y la crisis de derechos humanos y desprestigio del gobierno; ante el proteccionismo planteado por Donald Trump, América Latina es una opción de diversificación de mercados que México debe plantearse. 10

El desarrollo del Mercosur desde su creación por medio del Tratado de Asunción en 1991 hasta el 2014, es analizado por Heine (2014), quien identifica los cambios en el sistema internacional a los cuales respondió su creación, el proceso por el cual se estableció, las diferentes etapas por las cuales ha atravesado y los obstáculos que ha enfrentado; las concusiones refieren recomendaciones encaminadas a la consolidación del Mercosur, entre ellas la necesidad de que Brasil como único miembro capaz de sacar al Mercosur de su inercia, avance hacia una mayor institucionalización, ya que un Mercosur exitoso sería una gran carta de presentación para Brasil en África, Asia y el resto del mundo. 11

En un estudio más específico, Dussel (2018), analiza los posibles efectos del Acuerdo Integral y Progresivo para la Asociación Transpacífico (CPTPP) sobre la industria del calzado en México, este acuerdo vincula a México con dos economías de Latinoamérica: Perú y chile, el autor refiere que la economía mexicana ha otorgado muy significativos beneficios en términos arancelarios y de acceso a su mercado doméstico en el marco del Acuerdo de Asociación Transpacífico (TPP) y del CPTPP; concluye que el CPTPP no es conveniente para México en las condiciones actuales, pues el efecto en las exportaciones es pobre, mientras que su impacto en las importaciones es significativo, propiciando efectos negativos en el Producto Interno Bruto (PIB) y el empleo. 12

\section{Evidencia empírica del vínculo comercial de México con Latinoamérica}

Los tratados de libre comercio y los acuerdos que la economía mexicana ha logrado establecer en todo el mundo, son los elementos que facilitan el intercambio de los productos mexicanos con las diversas regiones del planeta; gracias a la integración que México ha logrado con el resto de las economías, se tiene un vasto mercado 
potencial. La Tabla 1, muestra los principales socios comerciales de México con su respectivo valor de las exportaciones para el año 2017; Estados Unidos supera por mucho al la Unión Europea, segundo socio comercial de México, la Asociación Latinoamericana de Integración (ALADI) se posiciona en tercer lugar, seguida de Canadá, Centroamérica y Japón.

\begin{tabular}{|l|c|}
\multicolumn{1}{c}{ Socio Comercial } & $\begin{array}{c}\text { Valor de las exportaciones } \\
\text { (Millones de dólares) }\end{array}$ \\
\hline Estados Unidos & 326,866 \\
\hline Unión Europea & $23,149.3$ \\
\hline ALADI & $14,254.6$ \\
\hline Canadá & 11,358 \\
\hline Centroamérica & 5,093 \\
\hline Japón & $4,038.5$
\end{tabular}

Tabla 1. Principales socios comerciales de México 2017. Fuente: Elaboración propia con datos de Secretaría de Economía (SE, 2017).

Pese a que México cuenta con una vasta red de acuerdos comerciales, es momento de analizar cada uno de ellos, con la finalidad de explorar nuevas oportunidades de mercado y estrategias que nos lleven a aprovechar estas relaciones comerciales. Es por ello, que el resto de la sección analiza las relaciones comerciales que México tiene con la región de América, las cuales se fundamentan en los acuerdos y tratados comerciales vigentes (ver tabla 2).

\begin{tabular}{|c|c|c|}
\hline Acuerdo/ Tratado & $\begin{array}{l}\text { Países } \\
\text { miembros }\end{array}$ & $\begin{array}{l}\text { Fecha entra } \\
\text { en vigor }\end{array}$ \\
\hline TLC México-Colombia & $\begin{array}{l}\text { México } \\
\text { Colombia }\end{array}$ & $\begin{array}{l}02 \text { Agosto } \\
2011\end{array}$ \\
\hline $\begin{array}{l}\text { TLC México- Costa } \\
\text { Rica }\end{array}$ & $\begin{array}{l}\text { México } \\
\text { Costa Rica }\end{array}$ & $\begin{array}{l}01 \text { Enero } \\
1995\end{array}$ \\
\hline TLC México- Nicaragua & $\begin{array}{l}\text { México } \\
\text { Nicaragua }\end{array}$ & 01 Julio 1998 \\
\hline TLC México- Chile & $\begin{array}{l}\text { México } \\
\text { Chile }\end{array}$ & $\begin{array}{l}01 \text { Agosto } \\
1999\end{array}$ \\
\hline $\begin{array}{l}\text { TLC México-Triángulo } \\
\text { del Norte }\end{array}$ & $\begin{array}{l}\text { México } \\
\text { El Salvador } \\
\text { Guatemala } \\
\text { Honduras }\end{array}$ & $\begin{array}{l}15 \text { Marzo } \\
2001\end{array}$ \\
\hline TLC México-Uruguay & $\begin{array}{l}\text { México } \\
\text { Uruguay }\end{array}$ & 15 Julio 2004 \\
\hline TLC Único & $\begin{array}{l}\text { México } \\
\text { Costa Rica } \\
\text { El Salvador } \\
\text { Guatemala } \\
\text { Honduras } \\
\text { Nicaragua }\end{array}$ & $\begin{array}{l}15 \text { Marzo } \\
2001\end{array}$ \\
\hline $\begin{array}{l}\text { Acuerdo de Integración } \\
\text { Comercial México-Perú }\end{array}$ & $\begin{array}{l}\text { México } \\
\text { Perú }\end{array}$ & $\begin{array}{l}01 \text { Febrero } \\
2012\end{array}$ \\
\hline $\begin{array}{l}\text { Acuerdo de } \\
\text { Complementación } \\
\text { Económica México- } \\
\text { Bolivia }\end{array}$ & $\begin{array}{l}\text { México } \\
\text { Bolivia }\end{array}$ & 07 Junio 2010 \\
\hline $\begin{array}{l}\text { ACE -55 México } \\
\text { MERCOSUR }\end{array}$ & $\begin{array}{l}\text { México } \\
\text { Argentina }\end{array}$ & $\begin{array}{l}01 \text { Enero } \\
2003\end{array}$ \\
\hline
\end{tabular}

\begin{tabular}{|c|c|c|}
\hline & $\begin{array}{l}\text { Bolivia } \\
\text { Brasil } \\
\text { Paraguay } \\
\text { Uruguay } \\
\text { Venezuela }\end{array}$ & \\
\hline ACE - 53 & $\begin{array}{l}\text { México } \\
\text { Brasil }\end{array}$ & 02 Mayo 2003 \\
\hline ALADI ACE 6 & $\begin{array}{l}\text { México } \\
\text { Argentina }\end{array}$ & $\begin{array}{l}01 \text { Enero } \\
2007\end{array}$ \\
\hline ALADI ACE 5 & $\begin{array}{l}\text { México } \\
\text { Uruguay }\end{array}$ & $\begin{array}{l}29 \text { Diciembre } \\
1999\end{array}$ \\
\hline ALADI AAP 29 & $\begin{array}{l}\text { México } \\
\text { Ecuador }\end{array}$ & 30 Abril 1983 \\
\hline ALADI AAP 4 & $\begin{array}{l}\text { México } \\
\text { Argentina } \\
\text { Brasil } \\
\text { Cuba } \\
\text { Ecuador } \\
\text { Paraguay } \\
\text { Uruguay }\end{array}$ & 10 Abril 2000 \\
\hline
\end{tabular}

Tabla 2. Acuerdos y Tratados Comerciales entre México y América Latina.

Fuente: Elaboración propia con datos de SE (2017).

La tabla 3, presenta el intercambio de dos vías entre México y los países de América Latina en el periodo 2008-2017; México obtuvo un saldo superavitario con: Colombia, Nicaragua, Chile, el Salvador, Guatemala, Honduras, Perú, Bolivia y Argentina; y un balance negativo con: Costa Rica, Uruguay, Paraguay y Brasil.

\begin{tabular}{|l|c|c|c|}
\hline \multicolumn{1}{|c}{ País } & Exportaciones & Importaciones & $\begin{array}{c}\text { Saldo } \\
\text { Balanza } \\
\text { Comercial }\end{array}$ \\
\hline Colombia & $\$ 3,987,230.00$ & $\$ 972,850.00$ & + \\
\hline Costa Rica & $\$ 918,010.00$ & $\$ 1,654,260.00$ & - \\
\hline Nicaragua & $\$ 647,440.00$ & $\$ 348,860.00$ & + \\
\hline Chile & $\$ 1,846,630.00$ & $\$ 1,698,750.00$ & + \\
\hline El Salvador & $\$ 636,140.00$ & $\$ 111,780.00$ & + \\
\hline Guatemala & $\$ 1,643,740.00$ & $\$ 513,910.00$ & + \\
\hline Honduras & $\$ 518,840.00$ & $\$ 354,450.00$ & + \\
\hline Uruguay & $\$ 225,730.00$ & $\$ 312,330.00$ & - \\
\hline Perú & $\$ 1,301,950.00$ & $\$ 558,380.00$ & + \\
\hline Bolivia & $\$ 149,890.00$ & $\$ 37,620.00$ & + \\
\hline Argentina & $\$ 1,573,800.00$ & $\$ 1,073,280.00$ & + \\
\hline Paraguay & $\$ 112,630.00$ & $\$ 115,770.00$ & - \\
\hline Brasil & $\$ 4,079,650.00$ & $\$ 4,575,080.00$ & - \\
\hline Venezuela & $\$ 1,567,910.00$ & $\$ 299,720.00$ & + \\
\hline Ecuador & $\$ 701,000.00$ & $\$ 140,530.00$ & + \\
\hline Cuba & $\$ 338,640.00$ & $\$ 17,360.00$ & + \\
\hline
\end{tabular}


Tabla 3. Intercambio de dos vías entre México y América Latina (Periodo: 2008-2017, en millones de dólares). Fuente: Elaboración propia con datos de SE (2017).

Durante el periodo de estudio, las exportaciones de México con destino a Latinoamérica fueron más significativas que las importaciones; a excepción de los cuatro países en donde se obtuvo un saldo de la balanza comercial negativo, el mayor saldo negativo fue con Costa Rica y ascendió a 736,250.00 millones de dólares (mdd), seguido de Brasil con un saldo de 495,430.00 mdd, Uruguay con $86,550.00$ mdd y finalmente Paraguay con un saldo de 3,140.00 mdd. Los datos demuestran que los productos mexicanos, tienen un alto índice de consumo en los mercados de Latinoamérica, lo que denota la excelente oportunidad de negocio en dicha región.

\begin{tabular}{|c|c|c|c|c|}
\hline \multirow{2}{*}{ Código } & \multirow{2}{*}{ Producto } & \multicolumn{3}{|c|}{ México exporta en mdd } \\
\hline & & 2015 & 2016 & 2017 \\
\hline 87 & $\begin{array}{l}\text { Automóviles } \\
\text { de turismo y } \\
\text { demás } \\
\text { vehículos de } \\
\text { transporte }\end{array}$ & 648.535 & 577.770 & 615.766 \\
\hline 33 & $\begin{array}{l}\text { Aceites } \\
\text { esenciales y } \\
\text { resinoides; } \\
\text { preparaciones } \\
\text { de perfumería }\end{array}$ & 154.48 & 147.204 & 139.038 \\
\hline 72 & $\begin{array}{c}\text { Fundición, } \\
\text { hierro y acero. }\end{array}$ & 245.006 & 144.439 & 156.282 \\
\hline \multirow[t]{3}{*}{30} & $\begin{array}{l}\text { Productos } \\
\text { farmacéuticos }\end{array}$ & 109.261 & 106.244 & 91.564 \\
\hline & & \multicolumn{3}{|c|}{ México importa en mdd } \\
\hline & & 2015 & 2016 & 2017 \\
\hline 27 & $\begin{array}{l}\text { Combustibles } \\
\text { minerales, } \\
\text { materias } \\
\text { bituminosas }\end{array}$ & 98.074 & 199.421 & 755.231 \\
\hline 87 & $\begin{array}{l}\text { Vehículos } \\
\text { terrestres, sus } \\
\text { partes y } \\
\text { accesorios }\end{array}$ & 157.014 & 191.843 & 178.073 \\
\hline 39 & $\begin{array}{l}\text { Plástico y sus } \\
\text { manufacturas }\end{array}$ & 122.393 & 147.074 & 134.121 \\
\hline 15 & $\begin{array}{c}\text { Grasas y } \\
\text { aceites } \\
\text { animales o } \\
\text { vegetales }\end{array}$ & 44.971 & 53.789 & 89.182 \\
\hline
\end{tabular}

Tabla 4. Comercio bilateral entre México y Colombia.

Fuente: Elaboración propia, datos de TradeMap (2018).

La tabla 4 presenta los principales productos que intercambian México y Colombia, se utilizan los dos primeros dígitos de la fracción arancelaria, seguido de la descripción del producto y el valor del comercio en mdd, para los años 2015, 2016 y 2017. El comercio entre estas dos economías es de tipo inter industrial, ya que, se importan y exportan productos con distintas características, de diferentes industrias y sectores, de México hacia Colombia se exportan más productos de manufactura de contenido tecnológico medio; en el 2017 la importación de combustibles minerales y materias butiminosas creció de forma exponencial, si bien, el saldo comercial de México con Colombia es positivo, las importaciones de México crecen a mayor ritmo que las exportaciones.

\begin{tabular}{|c|c|c|c|c|}
\hline \multirow{2}{*}{ Código } & \multirow{2}{*}{ Producto } & \multicolumn{3}{|c|}{ México exporta en mdd } \\
\hline & & 2015 & 2016 & 2017 \\
\hline 87 & $\begin{array}{c}\text { Vehículos } \\
\text { terrestres, sus } \\
\text { partes y } \\
\text { accesorios }\end{array}$ & 85.393 & 118.209 & 106.901 \\
\hline 85 & $\begin{array}{c}\text { Máquinas, } \\
\text { aparatos, } \\
\text { material } \\
\text { eléctrico, y sus } \\
\text { partes }\end{array}$ & 159.394 & 108.714 & 105.386 \\
\hline 84 & $\begin{array}{l}\text { Máquinas, } \\
\text { artefactos } \\
\text { mecánicos y } \\
\text { sus partes }\end{array}$ & 84.239 & 72.495 & 78.248 \\
\hline \multirow[t]{3}{*}{39} & $\begin{array}{l}\text { Plástico y sus } \\
\text { manufacturas }\end{array}$ & 67.121 & 66.502 & 69.341 \\
\hline & & \multicolumn{3}{|c|}{ México importa en mdd } \\
\hline & & 2015 & 2016 & 2017 \\
\hline 15 & $\begin{array}{c}\text { Grasas y } \\
\text { aceites } \\
\text { animales o } \\
\text { vegetales }\end{array}$ & 118.610 & 101.490 & 127.623 \\
\hline 85 & $\begin{array}{c}\text { Máquinas, } \\
\text { aparatos, } \\
\text { material } \\
\text { eléctrico, y sus } \\
\text { partes }\end{array}$ & 233.323 & 90.881 & 69.146 \\
\hline 90 & $\begin{array}{l}\text { Instrumentos y } \\
\text { aparatos de } \\
\text { óptica, } \\
\text { fotografía o } \\
\text { cinematografía }\end{array}$ & 48.278 & 62.911 & 48.414 \\
\hline 39 & $\begin{array}{l}\text { Plástico y sus } \\
\text { manufacturas }\end{array}$ & 22.583 & 28.259 & 27.191 \\
\hline
\end{tabular}

Tabla 5. Comercio bilateral entre México y Costa Rica. Fuente: Elaboración propia, datos de TradeMap (2018).

El intercambio comercial entre México y Costa Rica, tuvo un auge a partir de la firma del Tratado de libre Comercio entre ambas economías en 1994, actualmente los principales productos exportados de México hacia Costa Rica, recaen en el sector manufacturero (autos, autopartes, televisiones, refrigeradores, lavadoras); a su vez la economía mexicana importa aceite en bruto, circuitos integrados híbridos, tapas abre fácil, entre otros, (ver tabla 5).

El comercio entre México y Nicaragua, muestra una tendencia creciente en los últimos años; México figura entre los principales socios comerciales de Nicaragua, México vende a Nicaragua conductores eléctricos y de 
telefonía, aceites crudos de petróleo, y manufacturas de plástico, a su vez consume conductores eléctricos, carne, semillas, plantas medicinales y prendas de vestir, (ver tabla 6).

\begin{tabular}{|c|c|c|c|c|}
\hline \multirow{2}{*}{ Código } & \multirow{2}{*}{ Producto } & \multicolumn{3}{|c|}{ México exporta en mdd } \\
\hline & & 2015 & 2016 & 2017 \\
\hline 85 & $\begin{array}{l}\text { Máquinas, } \\
\text { aparatos, } \\
\text { material } \\
\text { eléctrico y sus } \\
\text { partes }\end{array}$ & 311.844 & 31.7495 & 307.337 \\
\hline 27 & $\begin{array}{l}\text { Combustibles } \\
\text { minerales, } \\
\text { materias } \\
\text { bituminosas }\end{array}$ & 95.638 & 77.871 & 78.843 \\
\hline 39 & $\begin{array}{l}\text { Plástico y sus } \\
\text { manufacturas }\end{array}$ & 67.696 & 66.903 & 67.470 \\
\hline \multirow[t]{2}{*}{84} & $\begin{array}{l}\text { Máquinas, } \\
\text { aparatos } \\
\text { mecánicos y } \\
\text { sus partes }\end{array}$ & 41.687 & 42.068 & 47.525 \\
\hline & & \multicolumn{3}{|c|}{ México importa en mdd } \\
\hline 85 & $\begin{array}{l}\text { Máquinas, } \\
\text { aparatos, } \\
\text { material } \\
\text { eléctrico y sus } \\
\text { partes }\end{array}$ & 409.525 & 515.796 & 184.118 \\
\hline 02 & $\begin{array}{c}\text { Carne y } \\
\text { despojos } \\
\text { comestibles }\end{array}$ & 22.722 & 28.065 & 45.138 \\
\hline 61 & $\begin{array}{l}\text { Prendas de } \\
\text { vestir y } \\
\text { complementos } \\
\text { de punto }\end{array}$ & 27.833 & 36.664 & 37.364 \\
\hline 12 & $\begin{array}{c}\text { Semillas, } \\
\text { frutos } \\
\text { diversos, } \\
\text { plantas } \\
\text { medicinales }\end{array}$ & 42.290 & 27.920 & 26.872 \\
\hline
\end{tabular}

Tabla 6. Comercio bilateral entre México y Nicaragua.

Fuente: Elaboración propia, datos de TradeMap (2018).

La tabla 7 resume el comercio bilateral entre México y Chile; México exporta: autos, autopartes, televisiones, computadoras y lociones capilares; a su vez, importa: cobre y sus manufacturas, madera y sus derivados, pescados y abonos, cabe señalar que la comercialización de las bebidas alcohólicas y los frutos muestran un importante y creciente dinamismo.

Con el Salvador, México mantiene crecientes e importantes relaciones comerciales, fundamentadas en el Tratado Único de Libre Comercio firmado entre los países centroamericanos y México. De acuerdo al Banco Central de Reserva (2018), los t-shirts o camisetas de punto son el principal producto exportado por El Salvador, y México se encuentra entre los principales países de destino, México ocupó el cuarto lugar en la lista de los principales importadores de El Salvador; México en contraparte exporta televisores, computadoras, automóviles y autopartes, (ver tabla 8).

\begin{tabular}{|c|c|c|c|c|}
\hline \multirow{2}{*}{ Código } & \multirow{2}{*}{ Producto } & \multicolumn{3}{|c|}{ México exporta en mdd } \\
\hline & & 2015 & 2016 & 2017 \\
\hline 87 & $\begin{array}{l}\text { Vehículos } \\
\text { terrestres y } \\
\text { sus partes }\end{array}$ & 365.849 & 364.122 & 504.288 \\
\hline 85 & $\begin{array}{l}\text { Máquinas, } \\
\text { aparatos, } \\
\text { material } \\
\text { eléctrico y sus } \\
\text { partes }\end{array}$ & 474.254 & 429.008 & 456.437 \\
\hline 84 & $\begin{array}{l}\text { Máquinas, } \\
\text { aparatos } \\
\text { mecánicos y } \\
\text { sus partes }\end{array}$ & 188.421 & 159.927 & 167332 \\
\hline \multirow[t]{2}{*}{33} & $\begin{array}{l}\text { Aceites } \\
\text { esenciales y } \\
\text { resinoides }\end{array}$ & 99.785 & 105.891 & 97.136 \\
\hline & & \multicolumn{3}{|c|}{ México importa en mdd } \\
\hline 74 & $\begin{array}{l}\text { Cobre y sus } \\
\text { manufacturas }\end{array}$ & 143.208 & 110.643 & 313.759 \\
\hline 44 & $\begin{array}{c}\text { Madera, } \\
\text { carbón vegetal } \\
y \\
\text { manufacturas }\end{array}$ & 267.812 & 221.188 & 180.856 \\
\hline 03 & $\begin{array}{l}\text { Pescados y } \\
\text { demás } \\
\text { invertebrados } \\
\text { acuáticos }\end{array}$ & 99.243 & 107.659 & 128.446 \\
\hline 31 & Abonos & 149.342 & 121.772 & 120.956 \\
\hline
\end{tabular}

Fuente: Elaboración propia, datos de TradeMap (2018).

\begin{tabular}{|c|c|c|c|c|}
\hline \multirow{2}{*}{ Código } & \multirow{2}{*}{ Producto } & \multicolumn{3}{|c|}{ México exporta en mdd } \\
\hline & & 2015 & 2016 & 2017 \\
\hline 85 & $\begin{array}{l}\text { Máquinas, } \\
\text { aparatos, } \\
\text { material } \\
\text { eléctrico y } \\
\text { sus partes }\end{array}$ & 105.263 & 77.089 & 105.509 \\
\hline 39 & $\begin{array}{c}\text { Plástico y } \\
\text { sus } \\
\text { manufacturas }\end{array}$ & 51.996 & 58.159 & 71.955 \\
\hline 87 & $\begin{array}{l}\text { Vehículos } \\
\text { terrestres y } \\
\text { sus partes }\end{array}$ & 30.004 & 30.693 & 42.986 \\
\hline \multirow[t]{2}{*}{84} & $\begin{array}{l}\text { Máquinas, } \\
\text { aparatos } \\
\text { mecánicos y } \\
\text { sus partes }\end{array}$ & 36.751 & 32.592 & 38.304 \\
\hline & & \multicolumn{3}{|c|}{ México importa en mdd } \\
\hline 85 & $\begin{array}{l}\text { Máquinas, } \\
\text { aparatos, } \\
\text { material }\end{array}$ & 44.918 & 26.055 & 53.886 \\
\hline
\end{tabular}




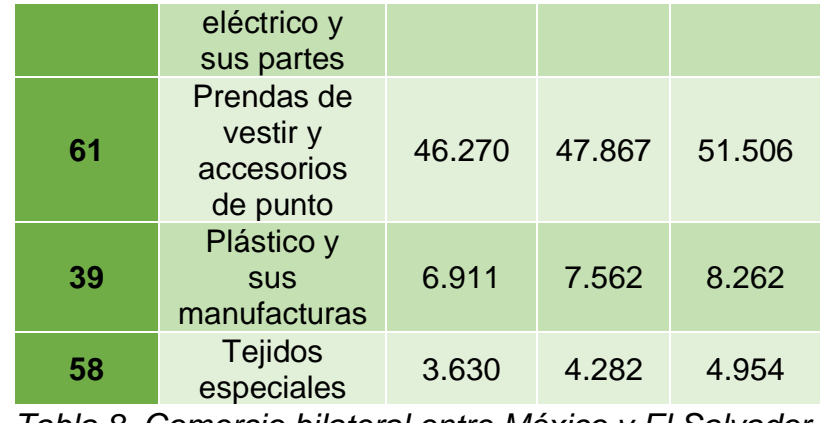

Tabla 8. Comercio bilateral entre México y El Salvador. Fuente: Elaboración propia, datos de TradeMap (2018).

\begin{tabular}{|c|c|c|c|c|}
\hline \multirow{2}{*}{ Código } & \multirow{2}{*}{ Producto } & \multicolumn{3}{|c|}{ México exporta en mdd } \\
\hline & & 2015 & 2016 & 2017 \\
\hline 85 & $\begin{array}{c}\text { Máquinas, } \\
\text { aparatos y } \\
\text { material } \\
\text { eléctrico, y sus } \\
\text { partes }\end{array}$ & 178.060 & 183.003 & 193.344 \\
\hline 33 & $\begin{array}{l}\text { Aceites } \\
\text { esenciales y } \\
\text { resinoides }\end{array}$ & 142.725 & 138.277 & 141.954 \\
\hline 39 & $\begin{array}{l}\text { Plástico y sus } \\
\text { manufacturas }\end{array}$ & 129.129 & 140.041 & 133.264 \\
\hline \multirow[t]{2}{*}{84} & $\begin{array}{l}\text { Máquinas, } \\
\text { artefactos } \\
\text { mecánicos y } \\
\text { sus partes }\end{array}$ & 135.306 & 89.521 & 87.786 \\
\hline & & \multicolumn{3}{|c|}{ México importa en mdd } \\
\hline 15 & $\begin{array}{l}\text { Grasas y } \\
\text { aceites } \\
\text { animales o } \\
\text { vegetales }\end{array}$ & 132.12 & 165.694 & 163.118 \\
\hline 40 & $\begin{array}{l}\text { Caucho y sus } \\
\text { manufacturas }\end{array}$ & 52.763 & 52.228 & 69.132 \\
\hline 61 & $\begin{array}{l}\text { Prendas y } \\
\text { complementos } \\
\text { de vestir, de } \\
\text { punto }\end{array}$ & 27.387 & 36.153 & 39.341 \\
\hline 22 & $\begin{array}{l}\text { Bebidas, } \\
\text { líquidos } \\
\text { alcohólicos y } \\
\text { vinagre }\end{array}$ & 21.113 & 21.299 & 26.789 \\
\hline
\end{tabular}

Tabla 9. Comercio bilateral entre México y Guatemala.

Fuente: Elaboración propia, datos de TradeMap (2018).

México es actualmente, el segundo socio comercial de Guatemala a nivel mundial y el primero a nivel Latinoamérica; a su vez, Guatemala es el sexto socio comercial de México en América Latina, dicha relación se basa el TLC Único que ambas regiones mantienen. De acuerdo al Banco de Guatemala, hasta septiembre de 2018 el producto que registro el más alto nivel de importación de México hacia Guatemala fueron las grasas y aceites comestibles, seguidas de caucho natural (hule), prendas de vestir de punto y bebidas; el producto que México más exporta a este mismo país son televisiones, artículos de perfumería, manufacturas de plástico (artículos de uso doméstico y para envasados) y refrigeradores, (Ver tabla 9).

De acuerdo al Banco Central de Honduras (2017), México es el cuarto proveedor más importante de Honduras en productos como aparatos y material eléctrico, y productos farmacéuticos. La relación comercial que mantienen estos países se basa en el Tratado de Libre Comercio suscrito entre México, El Salvador, Guatemala y honduras. México obtiene de Honduras: prendas de vestir, aparatos eléctricos y pescados (Ver tabla 10), las exportaciones de México tiene mayor valor agregado.

\begin{tabular}{|c|c|c|c|c|}
\hline \multirow{2}{*}{ Código } & \multirow{2}{*}{ Producto } & \multicolumn{3}{|c|}{ México exporta en mdd } \\
\hline & & 2015 & 2016 & 2017 \\
\hline 85 & $\begin{array}{c}\text { Máquinas, } \\
\text { aparatos y } \\
\text { material } \\
\text { eléctrico, y sus } \\
\text { partes }\end{array}$ & $\begin{array}{c}101.77 \\
7\end{array}$ & $\begin{array}{c}117.67 \\
8\end{array}$ & $\begin{array}{c}138.53 \\
5\end{array}$ \\
\hline 87 & $\begin{array}{c}\text { Vehículos } \\
\text { automóviles, y } \\
\text { demás } \\
\text { vehículos } \\
\text { terrestres }\end{array}$ & 34.376 & 40.052 & 50.453 \\
\hline 33 & $\begin{array}{l}\text { Aceites } \\
\text { esenciales y } \\
\text { resinoides }\end{array}$ & 35.825 & 40.332 & 37.701 \\
\hline \multirow[t]{2}{*}{39} & $\begin{array}{l}\text { Plástico y sus } \\
\text { manufacturas }\end{array}$ & 28126 & 30709 & 36488 \\
\hline & & \multicolumn{3}{|c|}{ México importa en mdd } \\
\hline 61 & $\begin{array}{l}\text { Prendas y } \\
\text { complementos } \\
\text { de vestir, de } \\
\text { punto }\end{array}$ & 91939 & 86014 & 100959 \\
\hline 99 & $\begin{array}{c}\text { Materias } \\
\text { especificadas }\end{array}$ & 65811 & 68581 & 77931 \\
\hline 85 & $\begin{array}{l}\text { Máquinas, } \\
\text { aparatos, } \\
\text { material } \\
\text { eléctrico, y sus } \\
\text { partes }\end{array}$ & 77533 & 79366 & 66023 \\
\hline 03 & $\begin{array}{l}\text { Pescados y } \\
\text { demás } \\
\text { invertebrados } \\
\text { acuáticos }\end{array}$ & 27069 & 45122 & 33874 \\
\hline
\end{tabular}

Tabla 10. Comercio bilateral entre México y Honduras. Fuente: Elaboración propia, datos de TradeMap (2018).

México absorbe el $4 \%$ de las exportaciones uruguayas, siendo así el séptimo comprador a nivel mundial de estos productos (EI Financiero, 2018). Ambos países tienen un Tratado de Libre Comercio desde 2004; entre los principales productos que México exporta a Uruguay están los vehículos de transporte para personas de cilindrada entre $1500 \mathrm{~m} 3$ y $3000 \mathrm{~cm} 3$, monitores y proyectores con pantalla plana, tractores de rueda con 
toma de fuerza, cajas de volteo, demás vehículos inferiores o igual a $5 \mathrm{t}$ para el transporte de mercancías, refrigeradores, congeladores con peso unitario inferior 0 igual a $200 \mathrm{~kg}$, teléfonos celulares, etc. (Secretaria de Economía, 2018). Las compras de México se centran en aceite, pieles, cereales y maderas, (ver tabla 11).

\begin{tabular}{|c|c|c|c|c|}
\hline \multirow{2}{*}{ Código } & \multirow{2}{*}{ Producto } & \multicolumn{3}{|c|}{ México exporta en mdd } \\
\hline & & 2015 & 2016 & 2017 \\
\hline 87 & $\begin{array}{l}\text { Vehículos } \\
\text { automóviles, } \\
\text { y demás } \\
\text { vehículos } \\
\text { terrestres }\end{array}$ & 67.297 & 29.838 & 63.571 \\
\hline 85 & $\begin{array}{c}\text { Máquinas, } \\
\text { aparatos y } \\
\text { material } \\
\text { eléctrico }\end{array}$ & 32.820 & 23.389 & 28.239 \\
\hline 84 & $\begin{array}{l}\text { Máquinas, } \\
\text { aparatos y } \\
\text { artefactos } \\
\text { mecánicos }\end{array}$ & 23.053 & 25.055 & 27.237 \\
\hline \multirow[t]{2}{*}{31} & Abonos & 7.648 & 10.400 & 22.965 \\
\hline & & \multicolumn{3}{|c|}{ México importa en mdd } \\
\hline 33 & $\begin{array}{l}\text { Aceites } \\
\text { esenciales y } \\
\text { resinoides }\end{array}$ & 84.683 & 87.582 & 95.456 \\
\hline 41 & $\begin{array}{l}\text { Pieles y } \\
\text { cueros }\end{array}$ & 83.963 & 85.415 & 76.355 \\
\hline 10 & Cereales & 40.377 & 40.291 & 61.570 \\
\hline 44 & $\begin{array}{c}\text { Madera, } \\
\text { carbón } \\
\text { vegetal y } \\
\text { manufacturas }\end{array}$ & 35.112 & 28.672 & 37.718 \\
\hline
\end{tabular}

Tabla 11. Comercio bilateral entre México y Uruguay.

Fuente: Elaboración propia, datos de TradeMap (2018).

México es un importante socio de Perú, ambos pertenecen a la Alianza del Pacífico junto a Colombia y Chile. Las principales exportaciones de México a Perú son: televisores, tractores, automotores, vehículos de transporte, refrigeradores, computadoras, y artículos de higiene, tocador y limpieza como acondicionadores, crema dental, desodorantes corporales, detergente líquido y fragancia. Dentro de las importaciones provenientes a México de origen peruano, las principales mercancías son: combustibles minerales, aceites minerales y productos de su destilación, plásticos y sus manufacturas y frutos comestibles, (ver tabla 12).

\begin{tabular}{|c|c|c|c|c|}
\hline & \multicolumn{4}{c}{ México exporta en mdd } \\
\hline \multirow{2}{*}{ Código } & Producto & 2015 & 2016 & 2017 \\
\hline $\mathbf{8 5}$ & $\begin{array}{l}\text { Máquinas, } \\
\text { aparatos y } \\
\text { material } \\
\text { eléctrico }\end{array}$ & 446.478 & 355.163 & 365.712 \\
\hline
\end{tabular}

\begin{tabular}{|c|c|c|c|c|}
\hline 87 & $\begin{array}{c}\text { Vehículos } \\
\text { automóviles, } \\
\text { y demás } \\
\text { vehículos } \\
\text { terrestres }\end{array}$ & 272.201 & 247.000 & 284.721 \\
\hline 84 & $\begin{array}{l}\text { Máquinas, } \\
\text { aparatos y } \\
\text { artefactos } \\
\text { mecánicos }\end{array}$ & 162.854 & 179.853 & 172.433 \\
\hline \multirow[t]{2}{*}{33} & $\begin{array}{l}\text { Aceites } \\
\text { esenciales y } \\
\text { resinoides }\end{array}$ & 95.158 & 96.460 & 81.046 \\
\hline & & \multicolumn{3}{|c|}{ México importa en mdd } \\
\hline 27 & $\begin{array}{l}\text { Combustibles } \\
\text { minerales, } \\
\text { materias } \\
\text { bituminosas }\end{array}$ & 326.461 & 218.058 & 139.405 \\
\hline 26 & $\begin{array}{l}\text { Minerales } \\
\text { metalíferos, } \\
\text { escorias y } \\
\text { cenizas }\end{array}$ & 45.489 & 35.214 & 43.615 \\
\hline 39 & $\begin{array}{l}\text { Plástico y sus } \\
\text { manufacturas }\end{array}$ & 23.633 & 30.846 & 34.998 \\
\hline 08 & $\begin{array}{l}\text { Frutas y } \\
\text { frutos } \\
\text { comestibles }\end{array}$ & 4.188 & 25.952 & 24.888 \\
\hline
\end{tabular}

Tabla 12. Comercio bilateral entre México y Perú. Fuente: Elaboración propia, datos de TradeMap (2018).

\begin{tabular}{|c|c|c|c|c|}
\hline \multirow{2}{*}{$\begin{array}{c}\text { Códig } \\
0\end{array}$} & \multirow{2}{*}{ Producto } & \multicolumn{3}{|c|}{ México exporta en mdd } \\
\hline & & 2015 & 2016 & 2017 \\
\hline 87 & $\begin{array}{c}\text { Vehículos } \\
\text { automóviles, y } \\
\text { demás } \\
\text { vehículos } \\
\text { terrestres }\end{array}$ & 28.095 & 25.118 & 49.755 \\
\hline 39 & $\begin{array}{l}\text { Plástico y sus } \\
\text { manufacturas }\end{array}$ & 29.622 & 20.371 & 26.278 \\
\hline 84 & $\begin{array}{l}\text { Máquinas, } \\
\text { aparatos y } \\
\text { artefactos } \\
\text { mecánicos }\end{array}$ & 24.135 & 19.749 & 25.168 \\
\hline \multirow[t]{2}{*}{33} & $\begin{array}{l}\text { Aceites } \\
\text { esenciales y } \\
\text { resinoides }\end{array}$ & 10.824 & 11.314 & 10.488 \\
\hline & & \multicolumn{3}{|c|}{ México importa en mdd } \\
\hline 80 & $\begin{array}{l}\text { Estaño y sus } \\
\text { manufacturas }\end{array}$ & 7.899 & 14.797 & 10.715 \\
\hline 65 & $\begin{array}{l}\text { Sombreros y } \\
\text { sus partes }\end{array}$ & 3.506 & 3.781 & 5.117 \\
\hline 41 & $\begin{array}{c}\text { Pieles (excepto } \\
\text { la peletería) y } \\
\text { cueros }\end{array}$ & 1.855 & 3.645 & 3.336 \\
\hline 44 & $\begin{array}{c}\text { Madera, y } \\
\text { manufacturas }\end{array}$ & 2.382 & 2.221 & 2.053 \\
\hline
\end{tabular}

Tabla 13. Comercio bilateral entre México y Bolivia. Fuente: Elaboración propia, datos de TradeMap (2018).

Según el Instituto Nacional de Estadística de Bolivia, (2018), México es el octavo socio comercial más importante de Bolivia. Su relación comercial se basa en 
la Asociación Latinoamericana de Integración (ALADI); entre los productos que más exporta México a Bolivia están vehículos de transporte con capacidad superior a 10 personas, polímeros, refrigeradores, computadoras, máquinas centrifugadoras y maquinaria agrícola; las importaciones de México están soportadas en estaño en bruto, cascos para sobrero, pieles y maderas, (ver tabla 13).

\begin{tabular}{|c|c|c|c|c|}
\hline \multirow{2}{*}{ Código } & \multirow{2}{*}{ Producto } & \multicolumn{3}{|c|}{ México exporta en mdd } \\
\hline & & 2015 & 2016 & 2017 \\
\hline 87 & $\begin{array}{c}\text { Vehículos } \\
\text { automóviles, } \\
\text { y demás } \\
\text { vehículos } \\
\text { terrestres }\end{array}$ & 585.674 & 638.148 & 744.991 \\
\hline 84 & $\begin{array}{l}\text { Máquinas, } \\
\text { aparatos y } \\
\text { artefactos } \\
\text { mecánicos }\end{array}$ & 135.962 & 191.854 & 147.624 \\
\hline 33 & $\begin{array}{l}\text { Aceites } \\
\text { esenciales y } \\
\text { resinoides. }\end{array}$ & 110.046 & 127.757 & 102.305 \\
\hline 85 & $\begin{array}{l}\text { Máquinas, } \\
\text { aparatos y } \\
\text { material } \\
\text { eléctrico }\end{array}$ & 138.769 & 62.062 & 86.302 \\
\hline & & \multicolumn{3}{|c|}{ México importa en mdd } \\
\hline 87 & $\begin{array}{l}\text { Vehículos } \\
\text { automóviles, } \\
\text { y demás } \\
\text { vehículos } \\
\text { terrestres }\end{array}$ & 319.437 & 284.542 & 237.330 \\
\hline 41 & $\begin{array}{l}\text { Pieles } \\
\text { (excepto la } \\
\text { peletería) y } \\
\text { cueros }\end{array}$ & 116.143 & 107.965 & 83.791 \\
\hline 84 & $\begin{array}{l}\text { Máquinas, } \\
\text { aparatos y } \\
\text { artefactos } \\
\text { mecánicos }\end{array}$ & 83.500 & 70.587 & 71.019 \\
\hline 76 & $\begin{array}{c}\text { Aluminio y } \\
\text { sus } \\
\text { manufacturas }\end{array}$ & 19.525 & 34.436 & 58.061 \\
\hline
\end{tabular}

Tabla 14. Comercio bilateral entre México y Argentina. Fuente: Elaboración propia, datos de TradeMap (2018).

Los principales productos exportados de México a Argentina son: vehículos de transporte, refrigeradores, computadoras, motores, impresoras, artículos de higiene personal, aparatos de telefonía y televisores; sus importaciones radican en: autopartes, pieles, motores, y aluminio en bruto (ver tabla 14). México es de los principales socios comerciales de Argentina, el Acuerdo de Complementación Económica (ACE) No. 6 es la base de las relaciones comerciales entre ambos países.

\begin{tabular}{|c|c|c|c|c|}
\hline \multirow{2}{*}{ Código } & \multirow{2}{*}{ Producto } & \multicolumn{3}{|c|}{$\begin{array}{c}\text { México exporta en } \\
\text { mdd }\end{array}$} \\
\hline & & 2015 & 2016 & 2017 \\
\hline 87 & $\begin{array}{l}\text { Vehículos } \\
\text { automóviles, } \\
\text { y demás } \\
\text { vehículos } \\
\text { terrestres }\end{array}$ & 20.454 & 15.974 & 34.459 \\
\hline 85 & $\begin{array}{l}\text { Máquinas, } \\
\text { aparatos y } \\
\text { material } \\
\text { eléctrico }\end{array}$ & 15.389 & 21.135 & 24.931 \\
\hline 84 & $\begin{array}{l}\text { Máquinas, } \\
\text { aparatos y } \\
\text { artefactos } \\
\text { mecánicos }\end{array}$ & 9.530 & 13.913 & 12.768 \\
\hline \multirow[t]{2}{*}{55} & $\begin{array}{l}\text { Fibras } \\
\text { sintéticas o } \\
\text { artificiales } \\
\text { discontinuas }\end{array}$ & 14.499 & 9.242 & 12.363 \\
\hline & & \multicolumn{3}{|c|}{ México importa en mdd } \\
\hline 12 & $\begin{array}{c}\text { Semillas y } \\
\text { frutos } \\
\text { diversos }\end{array}$ & 107.066 & 117.379 & 63.692 \\
\hline 30 & $\begin{array}{l}\text { Productos } \\
\text { farmacéuticos }\end{array}$ & 10.994 & 7.784 & 9.950 \\
\hline 41 & Pieles & 7.174 & 6.338 & 4.778 \\
\hline 85 & $\begin{array}{l}\text { Máquinas, } \\
\text { aparatos y } \\
\text { material } \\
\text { eléctrico }\end{array}$ & 69 & 126 & 861 \\
\hline
\end{tabular}

Tabla 15. Comercio bilateral entre México y Paraguay. Fuente: Elaboración propia, datos de TradeMap (2018).

México y Paraguay mantienen una relación comercial por medio del ACE, lo cual permite que México exporte: automóviles para transporte e más de 10 personas y transporte de mercancías, televisiones, cables, computadoras y refrigeradores; entre las principales importaciones procedentes de Paraguay destacan: la soja, los frutos oleaginosos, cacahuates, medicamentos, pieles, consolas y aparatos eléctricos, (ver tabla 15).

México es uno de los países de América Latina que mayor relación económica tiene con Brasil de la misma manera que Brasil es el octavo socio comercial de México a nivel mundial y el primero en Latinoamérica. México exporta a Brasil principalmente: automóviles de transporte para más de 10 personas y para el transporte de mercancías, aparatos eléctricos, para alumbrado, telefonía, radio, cables, motores, computadoras y productos químicos orgánicos. Las importaciones de México se enfocan en automóviles para transporte de personas y mercancías, motores de émbolo y pieles, (ver tabla 16). 


\begin{tabular}{|c|c|c|c|c|}
\hline \multirow{2}{*}{ Código } & \multirow{2}{*}{ Producto } & \multicolumn{3}{|c|}{ México exporta en mdd } \\
\hline & & 2015 & 2016 & 2017 \\
\hline 87 & $\begin{array}{l}\text { Vehículos } \\
\text { terrestres }\end{array}$ & 1311.851 & 1080.308 & 1293.846 \\
\hline 85 & $\begin{array}{l}\text { Máquinas, } \\
\text { aparatos y } \\
\text { material } \\
\text { eléctrico }\end{array}$ & 414.494 & 302.181 & 437.196 \\
\hline 84 & $\begin{array}{l}\text { Máquinas, } \\
\text { aparatos y } \\
\text { artefactos } \\
\text { mecánicos }\end{array}$ & 379.915 & 351.188 & 426.043 \\
\hline \multirow[t]{2}{*}{29} & $\begin{array}{l}\text { Productos } \\
\text { químicos } \\
\text { orgánicos }\end{array}$ & 280.020 & 274.169 & 264.718 \\
\hline & & \multicolumn{3}{|c|}{ México importa en mdd } \\
\hline 87 & $\begin{array}{c}\text { Vehículos } \\
\text { automóviles, y } \\
\text { demás } \\
\text { vehículos } \\
\text { terrestres }\end{array}$ & 836.204 & 812.510 & 998.684 \\
\hline 84 & $\begin{array}{l}\text { Máquinas, } \\
\text { aparatos y } \\
\text { artefactos } \\
\text { mecánicos }\end{array}$ & 890.226 & 804.846 & 860.272 \\
\hline 99 & $\begin{array}{l}\text { Materiales no } \\
\text { especificadas }\end{array}$ & 351.256 & 335.311 & 539.497 \\
\hline 41 & Pieles & 312.631 & 302.762 & 296.309 \\
\hline
\end{tabular}

Tabla 16. Comercio bilateral entre México y Brasil, mdd. Fuente: Elaboración propia, datos de Trade Map (2018).

\begin{tabular}{|c|c|c|c|c|}
\hline \multirow{2}{*}{ Código } & \multirow{2}{*}{ Producto } & \multicolumn{3}{|c|}{ México exporta en mdd } \\
\hline & & 2015 & 2016 & 2017 \\
\hline 10 & Cereales & 228.346 & 207.526 & 388.024 \\
\hline 19 & $\begin{array}{c}\text { Preparados a } \\
\text { base de } \\
\text { cereales }\end{array}$ & 52.968 & 24.309 & 134.299 \\
\hline 04 & $\begin{array}{l}\text { Productos } \\
\text { comestibles } \\
\text { de origen } \\
\text { animal }\end{array}$ & 996 & 4.993 & 84.382 \\
\hline \multirow[t]{2}{*}{84} & $\begin{array}{l}\text { Máquinas, } \\
\text { aparatos y } \\
\text { artefactos } \\
\text { mecánicos }\end{array}$ & 101.505 & 93.979 & 79.439 \\
\hline & & \multicolumn{3}{|c|}{ México importa en mdd } \\
\hline 76 & $\begin{array}{l}\text { Aluminio y } \\
\text { manufacturas }\end{array}$ & 18.387 & 26.726 & 28.139 \\
\hline 72 & $\begin{array}{l}\text { Fundición, } \\
\text { hierro y acero }\end{array}$ & 33.118 & 89.381 & 19.104 \\
\hline 28 & $\begin{array}{l}\text { Productos } \\
\text { químicos } \\
\text { orgánicos }\end{array}$ & 21.786 & 13.417 & 12.717 \\
\hline 48 & Papel y cartón & 1 & 739 & 11.899 \\
\hline
\end{tabular}

Tabla 17. Comercio bilateral entre México y Venezuela. Fuente: Elaboración propia, datos de TradeMap (2018).
El nivel de exportaciones mexicanas están sumamente presentes en la dieta venezolana principalmente productos como el maíz blanco (harinero), el trigo, el arroz y en menor cantidad el sorgo, además de preparaciones para la alimentación infantil, pastas alimenticias, extractos de malta, leche, nata, quesos, refrigeradores, lavadoras entre otros. En 2017, el país sudamericano se convirtió en el mayor receptor de maíz blanco mexicano, en 2014, la leche y crema mexicanas no tenían lugar en ese país, pero para 2016 las ventas ascendieron, lo mismo sucedió con las preparaciones de carne, pescado o de crustáceos y moluscos, Banxico (2014). Las exportaciones venezolanas con destino a México, radican principalmente en: aluminio $y$ manufacturas, productos férreos, amoniaco anhídrido, hidróxido de aluminio y rollos de papel y cartón, (ver tabla 17).

\begin{tabular}{|c|c|c|c|c|}
\hline \multirow{2}{*}{ Código } & \multirow{2}{*}{ Producto } & \multicolumn{3}{|c|}{ México exporta en mdd } \\
\hline & & 2015 & 2016 & 2017 \\
\hline 87 & $\begin{array}{c}\text { Vehículos } \\
\text { automóviles, y } \\
\text { demás } \\
\text { vehículos } \\
\text { terrestres }\end{array}$ & 50.842 & 37.856 & 133.243 \\
\hline 30 & $\begin{array}{l}\text { Productos } \\
\text { farmacéuticos }\end{array}$ & 75.236 & 63.827 & 66.858 \\
\hline 84 & $\begin{array}{l}\text { Máquinas, } \\
\text { artefactos } \\
\text { mecánicos y } \\
\text { sus partes }\end{array}$ & 56.322 & 51.541 & 60.664 \\
\hline \multirow[t]{2}{*}{85} & $\begin{array}{l}\text { Máquinas, } \\
\text { aparatos y } \\
\text { material } \\
\text { eléctrico }\end{array}$ & 66.804 & 28.526 & 56.573 \\
\hline & & \multicolumn{3}{|c|}{ México importa en mdd } \\
\hline 18 & $\begin{array}{l}\text { Cacao y sus } \\
\text { preparaciones }\end{array}$ & 37.774 & 71.015 & 59.127 \\
\hline 15 & $\begin{array}{c}\text { Grasas y } \\
\text { aceites } \\
\text { animales o } \\
\text { vegetales }\end{array}$ & 23.132 & 28.099 & 17.703 \\
\hline \multirow[t]{2}{*}{16} & $\begin{array}{l}\text { Preparaciones } \\
\text { de carne o } \\
\text { pescado }\end{array}$ & 40.383 & 30.481 & 13.824 \\
\hline & $\begin{array}{c}\text { Productos } \\
\text { farmacéuticos }\end{array}$ & 12361 & 5.921 & 7.562 \\
\hline
\end{tabular}

Tabla 18. Comercio bilateral entre México y Ecuador. Fuente: Elaboración propia, datos de TradeMap (2018).

Entre los principales productos de exportación de México a Ecuador, se tienen: vehículos de transporte para más de 10 personas, automotores y demás autopartes y accesorios, medicamentos, refrigeradores, lavadoras, computadoras, secadoras, artículos de grifería, televisores, aparatos de telefonía y grabadoras; a su vez México importa: cacao y sus derivados (chocolate y pasta 
de cacao), aceite de palma, aceite de coco y en menor medida otros aceites de origen vegetal y animal, medicamentos, y preparaciones y conservas de pescado, crustáceos y moluscos, (ver tabla 18).

\begin{tabular}{|c|c|c|c|c|}
\hline \multirow{2}{*}{ Código } & \multirow{2}{*}{ Producto } & \multicolumn{3}{|c|}{ México exporta en mdd } \\
\hline & & 2015 & 2016 & 2017 \\
\hline 76 & $\begin{array}{l}\text { Aluminio y } \\
\text { sus } \\
\text { manufacturas }\end{array}$ & 34.806 & 34.189 & 36.034 \\
\hline 39 & $\begin{array}{l}\text { Plástico y sus } \\
\text { manufacturas }\end{array}$ & 56.317 & 29.984 & 35.953 \\
\hline 23 & $\begin{array}{l}\text { Residuos y } \\
\text { desperdicios } \\
\text { de las } \\
\text { industrias } \\
\text { alimentarias }\end{array}$ & 26.385 & 30.199 & 31.745 \\
\hline \multirow[t]{2}{*}{84} & $\begin{array}{l}\text { Máquinas, } \\
\text { aparatos y } \\
\text { artefactos } \\
\text { mecánicos }\end{array}$ & 20.992 & 24.499 & 23.476 \\
\hline & & \multicolumn{3}{|c|}{ México importa en mdd } \\
\hline 22 & $\begin{array}{l}\text { Bebidas, } \\
\text { líquidos } \\
\text { alcohólicos y } \\
\text { vinagre }\end{array}$ & 2.096 & 2.816 & 3.362 \\
\hline 24 & $\begin{array}{l}\text { Tabaco y } \\
\text { elaborados }\end{array}$ & 2.171 & 2.187 & 2.403 \\
\hline 30 & $\begin{array}{c}\text { Productos } \\
\text { farmacéuticos }\end{array}$ & 335 & 147 & 866 \\
\hline 41 & Pieles & 778 & 572 & 762 \\
\hline
\end{tabular}

Tabla 19. Comercio bilateral entre México y Cuba. Fuente: Elaboración propia, datos de Trade Map (2018).

La relación comercial entre México y Cuba tiene como base el Acuerdo de Complementación Económica Numero 51 (ACE51). México es uno de los principales socios comerciales de Cuba, luego de Venezuela y Brasil. En los principales productos que exporta México a Cuba están: recipientes de aluminio, perfiles de aluminio, polímeros de etileno, preparados para alimentos de animales y refrigeradores. A su vez, las importaciones más importantes de México provenientes de Cuba recaen en: alcohol etílico, aguardientes, licores, cerveza de malta, puros de tabaco, productos inmunológicos y pieles, (ver tabla 19).

\section{Conclusiones}

A lo largo del tiempo, han sido diversos los momentos en que tanto la literatura como los hacedores de política económica, han argumentado la necesidad que tiene México en relación con su diversificación de mercados, principalmente por el lado de las exportaciones; y es que, desde la implementación del TLCAN en enero de 1994, la economía mexicana ha forjado una fuerte dependencia en torno a la economía de Estados Unidos, la ubicación geográfica, la riqueza de recursos naturales, el costo de la mano de obra, entre otros factores, han posicionado
México como importante proveedor de Estados Unidos, y si bien, la relación comercial con Canadá de igual forma se fortaleció con el TLCAN, la integración comercial de México con el mundo se ve reflejada en su balanza comercial con la economía norteamericana.

En 2017, poco más del $80 \%$ de las exportaciones de México, se colocaron en Estados Unidos, por ello la actual situación de incertidumbre ante sucesos como la renegociación del TLCAN, la guerra comercial, las recientes políticas proteccionistas de Estados Unidos y la normalización de la política monetaria en Estados Unidos; obligan al análisis de búsqueda de nuevos mercados que permitan a los empresarios mexicanos, y sobre todo a un porcentaje relevante de la gran cantidad de Pequeñas y Medianas empresas, exportar a otros países, Latinoamérica es un buen mercado, al día de hoy se tienen 16 Tratados y Acuerdos comerciales con dicha región, y durante el periodo de estudio (2008-2017) es visible la existencia de un amplio comercio inter industrial entre México y cada país de Latinoamérica, resaltando a Colombia, Brasil y Chile principales socios comerciales de la zona.

Un primer acercamiento para explorar la actual dinámica comercial entre México y las economías de América Latina, permite identificar las fortalezas que cada país tiene para integrarse a la economía mundial, América Latina tiene abundantes recursos naturales, es justo ese el motivo por el que China ha trabajado para posicionarse como un importante socio en diversos países de la región; México a diferencia del resto mantiene un estrecho vínculo con América del Norte por ello, se ha insertado en las cadenas globales de producción, principalmente dentro del sector automotriz, y actualmente mantiene cierto nivel de productividad en procesos productivos de uso intensivo de mano de obra.

El proceso de renegociación del TLCAN, mostró que una dependencia absoluta en materia comercial torna a la economía mexicana en extremo vulnerable, si bien, México está fuertemente vinculado a Estados Unidos, al hablar de una diversificación de mercados con Latinoamérica, México ya se sitúa en rakings mundiales como exportador de bienes cuyo proceso de producción requiere el uso intensivo de mano de obra, y que además sus fabricación se caracteriza por estar dentro de cadenas de producción global, entre ellos: automóviles, pantallas y computadoras; por tanto, ssi es posible mantener y fortalecer la principal relación comercial de México, a la par que se fomenta una creciente y paulatina diversificación de mercados.

\section{Referencias}

[1] Luiselli C, Brasil y México: el acercamiento necesario. Revista Mexicana de Política Exterior. 2010; 90: 9-50.

[2] Granguillhome R, Las relaciones económicas de México con América Latina y El Caribe 1988 1994. Revista Mexicana de Política Exterior. 2012: 166-176.

[3] Ramos A, México ante el renovado espíritu integracionista en América Latina y el Caribe. Revista mexicana de política exterior. 2003: 135165 .

[4] Dussel E, Análisis sobre el acuerdo integral y progresivo de asociación transpacífico (CPTPP) y su potencial efecto en la cadena del calzado. Cámara de la Industria del Calzado del Estado de Guanajuato. 2018. 
[5] Puchet M, La integración regional de México: condicionantes y oportunidades por su doble pertenencia a América del Norte y a Latinoamérica. Economía UNAM. 2007; 8(23): 34.

[6] Herrada H, Centroamérica y el Caribe: atención prioritaria de la cooperación mexicana regional. Revista Mexicana de Política Exterior, 2014: 115-129.

[7] Icaza C, México, actor con responsabilidad global: jugador en nuevos tableros. Revista Mexicana de Política Exterior. 2014; 100: 9-48.

[8] Flores S, La Alianza del Pacífico: una apuesta para la libre movilidad y la integración. Revista Mexicana de Política Exterior, enero-abril 2016: 87-108.

[9] Covarrubias A, El reacomodo de México en una América Latina cambiante: de la euforia democrática a la introversión. Investigación y análisis, Pensamiento Propio. 2017; 44: 325-350.

[10] Heine J, ¿El Mercosur está marcando el paso? La política de la integración regional en el Cono Sur. Revista Mexicana de Política Exterior, 2014: 81-101. 